PENELITIAN

\title{
Keamanan Penggunaan Propofol Auto-Coinduction Dibandingkan Dengan Midazolam Coinduction Berdasarkan Perubahan Hemodinamik Pada Induksi Anestesi Pasien Yang Dilakukan General Anestesi
}

\section{Comparison of Propofol Auto-Coinduction to Midazolam Coinduction Safety Based On Hemodynamic Parameters in Patients Undergoing General Anesthesia}

I Nyoman Yesua ${ }^{\bowtie}$, Puger Rahardjo, Pesta Parulian Maurid Edwar

Bagian Anestesiologi dan Terapi Intensif, Fakultas Kedokteran, Universitas Airlangga/ RSUD Dr. Soetomo, Surabaya, Indonesia

${ }^{\bowtie}$ Korespondensi: inyesua@gmail.com

\begin{abstract}
Background: The choice of anesthesia drugs for induction is crucial for an anaesthesiologist and is based on pharmacodynamic effects towards the cardiovascular system.

Objective: To analyze whether propofol auto-coinduction (pre-dosing propofol) can be used as an alternative to midazolam as a co-induction drug, in terms of patient safety (hemodynamic changes that occur) and costs incurred.

Methods: This single blind group pre-post test design experimental study involved patients who underwent elective surgery with general anesthesia in the Operating Room of Dr. Soetomo Hospital Surabaya in September-October 2018. Two groups of patients received midazolam $0.03 \mathrm{mg} / \mathrm{KgBW}$ (group $M, n=26$ ) and propofol $0.4 \mathrm{mg} / \mathrm{KgBW}$ (group $M, n=26)$ respectively 2 minutes before induction with propofol titration until verbal contact was lost. The dose of propofol used, blood pressure before and after induction and the induction cost are recorded.

Results: The pre-induced MAP in group $M$ was $96,35 \pm 11,366 \mathrm{mmHg}$ and in group $P$ was 90,54 $\pm 7,732 \mathrm{mmHg}$, while the post-induction MAP in group $M$ was 79,96 $\pm 9,21 \mathrm{mmHg}$ and in group $P$ was 73,96 $\pm 5,03 \mathrm{mmHg}(p=0,037)$. Total cost spent in group $M$ was IDR $7.890 \pm 1.448,89$ while in group $P$ was IDR $7.082 \pm 1.403,89(p=0,047)$.

Conclusion: There were significant differences in MAP changes by propofol autocoinduction compared to midazolam co-induction. There were no significant differences in the blood pressure, heart rate and propofol dose between the two groups. Induction cost in the propofol auto-coinduction group was significantly lower.
\end{abstract}

Keywords: drugs; general anesthesia; hemodynamic safety; midazolam co-induction; propofol auto-coinduction

Volume 11, Nomor 1, Tahun 2019 


\begin{abstract}
ABSTRAK
Latar Belakang: Pemilihan obat anestesi untuk induksi bagi seorang ahli anestesi merupakan hal yang krusial dan didasarkan atas efek farmakodinamik terhadap sistem kardiovaskular.
\end{abstract}

Tujuan: Menganalisa apakah penggunaan propofol auto-coinduction (pre-dosing propofol) dapat digunakan sebagai alternatif midazolam sebagai obat coinduction, dilihat dari segi keamanan pasien (perubahan hemodinamik yang terjadi) dan biaya yang dikeluarkan.

Metode: Penelitian eksperimental dengan desain pre-posttest single blind group ini melibatkan 52 pasien yang menjalani operasi elektif dengan anestesi umum di Kamar Operasi Gedung Bedah Pusat Terpadu (GBPT) RSUD Dr. Soetomo Surabaya pada bulan September-Oktober 2018. Dua kelompok pasien masing-masing mendapatkan midazolam 0,03 mg/KgBB (kelompok $\mathrm{M}, \mathrm{n}=26$ ) dan propofol 0,4 mg/KgBB (kelompok $\mathrm{P}, \mathrm{n}=26) 2$ menit sebelum induksi dengan propofol titrasi sampai hilang kontak verbal. Dosis propofol yang digunakan, tekanan darah sebelum dan sesudah dilakukan induksi serta biaya induksi dicatat.

Hasil: Rerata Arterial Pressure (MAP) pra-induksi pada kelompok M adalah 96,35 $\pm 11,366 \mathrm{mmHg}$ dan pada kelompok $\mathrm{P} 90,54 \pm 7.732 \mathrm{mmHg}$, sedangkan MAP pascainduksi pada kelompok M sebesar $79.96 \pm 9.21 \mathrm{mmHG}$ dan pada kelompok $\mathrm{P}$ adalah $73,96 \pm 5,03 \mathrm{mmHg}(\mathrm{p}=0,037)$. Total biaya yang digunakan pada kelompok $\mathrm{M}$ adalah $\mathrm{Rp}$. $7.890 \pm 1.448 .89$ sedangkan pada kelompok P Rp. $7.082 \pm 1.403 .89$ ( $\mathrm{p}=0.047)$.

Kesimpulan: Terdapat perbedaan bermakna pada perubahan MAP yang disebabkan oleh penggunaan propofol auto-coinduction bila dibandingkan dengan midazolam coinduction. Tidak terdapat perbedaan signifikan penurunan tekanan darah dan nadi, serta dosis propofol yang digunakan antara kedua kelompok. Biaya induksi pada kelompok autocoinduction propofol secara signifikan lebih rendah.

Kata kunci: anestesi umum; keamanan hemodinamik; midazolam co-induction; obat; propofol auto-coinduction

\section{PENDAHULUAN}

Induksi anestesi merupakan suatu hal yang krusial bagi seorang ahli anestesi, dikarenakan berhubungan dengan perubahan hemodinamik dan fisiologi tubuh. ${ }^{1}$ Pemilihan obat anestesi untuk induksi sebagian besar didasarkan atas efek farmakodinamik, terutama dengan mempertimbangkan efek terhadap sistem kardiovaskular. ${ }^{2}$

Propofol merupakan obat anestesi intravena yang cukup baik untuk induksi anestesi, dikarenakan onset yang cepat dengan durasi yang singkat, memberikan kondisi persiapan intubasi yang baik dan efek samping pascaoperasi (seperti mual dan muntah) yang minimal (bila dibandingkan dengan Thiopental). ${ }^{3}$ Saat ini lebih dari $70 \%$ propofol digunakan sebagai sedasi intravena di kamar operasi, ruang diagnostik, dan ruang intensif. ${ }^{4}$ Namun penggunaan propofol sebagai agen induksi tunggal berhubungan dengan terjadinya penurunan tekanan darah, dimana semakin besar dosis maka perubahan tekanan darah juga semakin signifikan. ${ }^{5}$

Berbagai cara digunakan untuk mengurangi dosis propofol yang digunakan, salah satunya dengan co- 
induction. Co-induction didefinisikan sebagai penggunaan obat sedatif dosis kecil atau obat anestesi lain dengan tujuan untuk mengurangi dosis obat induksi, efek samping yang terjadi dan biaya obat. ${ }^{1}$ Beberapa obat dengan efek sinergis (midazolam, fentanyl, sufentanyl, alfentanil, ketamin) telah digunakan sebagai obat co-induction. Namun pada prakteknya pemberian midazolam 0,03 mg/kgBB (sekitar $2 \mathrm{mg}$ pada pasien dewasa sehat) diterima secara luas. ${ }^{6}$ Midazolam co-induction banyak dipakai pada induksi anestesi di RSUD Dr. Soetomo. Dari data bulan Januari sampai Juni 2017, sebanyak $86,3 \%$ pasien yang dilakukan anestesi umum menggunakan propofol sebagai obat induksi dan midazolam coinduction. ${ }^{7}$ Propofol sendiri juga dapat digunakan sebagai obat co-induction. Pemberian propofol predosing 0,4 $\mathrm{mg} / \mathrm{KgBB}$ menghasilkan pengurangan dosis propofol setara dengan midazolam. ${ }^{8}$ Pada penelitian yang dilakukan Sanket, dkk, pemberian predosing propofol dapat mengurangi $27,69 \%$ kebutuhan dosis induksi propofol. ${ }^{9}$

Pada penelitian lain oleh Rilin Karlo, dkk, dikatakan bahwa penggunaan predosing propofol mempunyai efek samping perubahan hemodinamik yang kecil. ${ }^{10}$ Bila penggunaan Propofol predosing bisa mengurangi dosis propofol dan tidak terjadi perubahan hemodinamik yang signifikan, maka dilihat dari segi pembiayaan akan terlihat bahwa propofol lebih menguntungkan. Penggunaan midazolam sebagai obat $c o$ induction, akan membuat penggunaan dua obat berbeda, yang dilihat dari segi ekonomi akan menambah biaya.

Berdasarkan pemikiran tersebut, maka penelitian ini bertujuan untuk menganalisa apakah penggunaan propofol auto-coinduction (predosing propofol) dapat digunakan sebagai alternative midazolam sebagai obat $\mathrm{co}$ induction, dilihat dari segi keamanan pasien (perubahan hemodinamik yang terjadi) dan biaya yang harus dikeluarkan. Kami berharap hasil penelitian ini dapat digunakan untuk meningkatkan kualitas pelayanan Departemen Anestesiologi dan Terapi Intensif Surabaya.

\section{METODE}

Penelitian eksperimental dengan desain pre-post test single blind group ini melibatkan pasien yang menjalani operasi elektif dengan general anestesi di Kamar Operasi Gedung Bedah Pusat Terpadu (GBPT) RSUD Dr. Soetomo Surabaya pada bulan SeptemberOktober 2018. Kriteria inklusi meliputi usia 18-55 tahun, PS ASA I-II, dan BMI $18-28 \mathrm{~kg} / \mathrm{m}^{2}$. Pasien dengan tekanan darah sistolik $<90 \mathrm{mmHg}$, pasien dengan jalan napas sulit dan penggunaan analgetik opioid jangka panjang dieksklusikan dari penelitian ini.

Pasien yang masuk kedalam kriteria inklusi dibagi kedalam 2 kelompok. Kelompok pertama (M) mendapatkan midazolam $0,03 \mathrm{mg} / \mathrm{KgBB} 2$ menit sebelum induksi. Kelompok kedua $(\mathrm{P})$ mendapatkan propofol $0,4 \mathrm{mg} / \mathrm{KgBB} 2$ menit sebelum induksi. Tekanan darah diukur dengan non-invasive arterial blood pressure monitor sebelum dilakukan induksi. Setelah 2 menit pemberian midazolam (M) maupun propofol (P), kedua kelompok pasien diberikan propofol titrasi sampai hilang kontak verbal dan dosis propofol yang digunakan dicatat dan tekanan darah pasca induksi diukur. Biaya induksi dihitung sesuai jumlah ampul propofol dan midazolam yang digunakan, dikalikan dengan harga perampul dan dinyatakan dalam rupiah (Rp). Data 
penelitian ini disajikan dalam bentuk tabel. Data hasil penelitian ditabulasi dan dianalisis dengan Independent t-test (signifikan pada $\mathrm{p}<0.05$ ). Seluruh pasien yang terlibat diberi penjelasan lisan dan tertulis mengenai penelitian dan memberi persetujuan tertulis untuk terlibat dalam penelitian. Penelitian ini mendapatkan ijin dari Komite Etik Penelitian Fakultas Kedokteran Universitas Airlangga.

\section{HASIL}

Didapatkan 52 pasien yang memenuhi kriteria inklusi, dengan perincian 26 pasien dalam kelompok $\mathrm{M}$ (induksi anestesi menggunakan co-induction midazolam) dan kelompok $\mathrm{P}$ (induksi Anestesi menggunakan propofol autocoinduction). Karakteristik subjek penelitian tertera dalam tabel dibawah ini.

Tabel 1. Karakteristik subjek penelitian

\begin{tabular}{llll} 
Kelompok & Midazolam (M) n: 26 & Propofol (P) n: 26 & $\mathrm{p}$ \\
\hline Umur (th) & $39.92 \pm 11.32$ & $40.27 \pm 11.82$ & 0.915 \\
Berat Badan (Kg) & $60.19 \pm 9.37$ & $59.85 \pm 9.58$ & 0.896 \\
Tinggi badan (cm) & $159.88 \pm 8.35$ & $160.08 \pm 7.32$ & 0.930 \\
BMI (Kg/m $\left.{ }^{2}\right)$ & $23.512 \pm 2.72$ & $23.562 \pm 2.65$ & 0.947 \\
PS ASA (1/2) & $9 / 17$ & $10 / 16$ & 1.000 \\
Jenis Kelamin & $12 / 14$ & $14 / 12$ & 0.782 \\
(L/P) & & & \\
\hline
\end{tabular}

Tabel 1 menunjukkan bahwa hasil uji independent T-test yang menganalisa perbedaan karakteristik antara kedua kelompok berdasarkan umur subjek, berat badan, tinggi badan, dan BMI semuanya bernilai $(p>0,05)$. Untuk data distribusi PS ASA dan jenis kelamin di tiap kelompok dilakukan uji Fisher's exact test, semuanya bernilai ( $\mathrm{p}>0.005$ ). Hal ini berarti perbedaan karakteristik fisik subjek secara statistik tidak bermakna, atau dengan kata lain kedua kelompok tersebut homogen berdasarkan variabel umur, berat badan, tinggi badan, dan BMI.

Hasil perbandingan perubahan tekanan darah, nadi dan MAP pra dan pascainduksi anestesi disajikan pada tabel 2.

Tabel 2. Perbandingan perubahan tekanan darah, nadi dan MAP

\begin{tabular}{|c|c|c|c|c|c|c|}
\hline \multirow{2}{*}{ Variabel } & $\begin{array}{l}\text { Midazolam } \\
\text { (M) }\end{array}$ & Propofol (P) & $\mathrm{p}$ & & & \\
\hline & Prainduksi & Pascainduksi & Prainduksi & Pascanduksi & & \\
\hline \multirow{2}{*}{$\begin{array}{l}\text { TD } \\
\text { Sistolik } \\
\text { (mmHg) }\end{array}$} & Rerata & 123.31 & 99.31 & 120.58 & 100.56 & \multirow{2}{*}{0.520} \\
\hline & SD & 11,238 & 17.23 & 10,195 & 5.07 & \\
\hline \multirow{2}{*}{$\begin{array}{l}\text { TD } \\
\text { Diastolik } \\
\text { (mmHg) }\end{array}$} & Rerata & 77.38 & 66.15 & 77.04 & 62.62 & \multirow{2}{*}{0.403} \\
\hline & SD & 16,437 & 10.41 & 8,407 & 6.054 & \\
\hline \multirow{2}{*}{$\begin{array}{l}\text { MAP } \\
(\mathrm{mmHg})\end{array}$} & Rerata & 96.35 & 79.96 & 90.54 & 73.96 & \multirow{2}{*}{0.037} \\
\hline & $\mathrm{SD}$ & 11,366 & 9.21 & 7,732 & 5.03 & \\
\hline \multirow{2}{*}{$\begin{array}{l}\text { Nadi } \\
\text { (x/menit) }\end{array}$} & Rerata & 88.35 & 85.04 & 87.46 & 86.38 & \multirow{2}{*}{0.676} \\
\hline & SD & 9,130 & 12.54 & 6,307 & 10.46 & \\
\hline
\end{tabular}


Tabel 2 menunjukkan hasil uji Mann whitney untuk variabel TD sistolik, TD diastolik dan MAP. Tidak ada pebedaan bermakna secara statistic terhadap perubahan tekanan darah sistolik dan tekanan darah diastolik pada kelompok propofol dibandingkan kelompok midazolam. Namun didapatkan perbedaan yang bermakna secara statistik untuk perubahan MAP. Untuk variabel nadi dilakukan uji independent T-Test, dan hasilnya tidak didapatkan perbedaan yang bemakna pada kelompok propofol dibandingkan dengan kelompok midazolam. Hasil perbandingan jumlah propofol yang digunakan disajikan pada Tabel 3.

Tabel 3. Perbandingan jumlah propofol yang digunakan

\begin{tabular}{llll}
\hline Variabel & Midazolam $(\mathrm{M})$ & Propofol $(\mathrm{P})$ & $\mathrm{p}$ \\
\hline Total propofol $(\mathrm{mL})$ & $8.04 \pm 1.755$ & $8.31 \pm 1.850$ & 0.593 \\
\hline
\end{tabular}

Tabel 3 menunjukkan hasil uji independent T-test untuk total propofol yang digunakan pada kelompok midazolam dan kelompok propofol. Bila dibandingkan keduanya, hasilnya tidak didapatkan perbedaan bermakna secara statistik. Hasil perbandingan jumlah biaya yang digunakan disajikan pada Tabel 4

Tabel 4. Perbandingan total harga yang digunakan

\begin{tabular}{llll}
\hline Variabel & Midazolam (M) & Propofol (P) & $\mathrm{p}$ \\
\hline Total Biaya (Rp) & $7890 \pm 1448.89$ & $7082 \pm 1403.89$ & 0.047 \\
\hline
\end{tabular}

Tabel 4 menunjukkan hasil uji independent T-test untuk perbedaan biaya yang digunakan kelompok midazolam dan kelompok propofol. Hasilnya didapatkan perbedaan yang signifikan.

\section{PEMBAHASAN}

Induksi anestesi dengan menggunakan propofol secara konvensional, dengan dosis 1-2 $\mathrm{mg} / \mathrm{KgBB}$ telah diketahui berhubungan dengan penurunan tekanan darah. ${ }^{11}$ Pada penelitian oleh Hug, dkk, dari 2500 pasien yang dilakukan induksi dengan propofol dilaporkan terjadi penurunan tekanan darah sistolik dibawah $90 \mathrm{mmHg}$ sebanyak $16 \%$. Dimana episode penurunan tekanan darah terjadi 10 menit awal induksi. ${ }^{12}$ Beberapa penelitian lain yang mengukur perubahan MAP pasien pada pemberian propofol dosis $2,5-3 \mathrm{mg} / \mathrm{KgBB}$, didapatkan penurunan $22-33 \%$ dari MAP awal. Hal ini berhubungan dengan vasodilatasi sehingga terjadi penurunan cardiac output setelah induksi dengan propofol. ${ }^{13}$

Untuk mengurangi dosis propofol yang digunakan, penggunaan obat yang memiliki efek sinergis dan telah diteliti dapat digunakan, diantaranya golongan benzodiazepin, ketamin dan opioid. ${ }^{10}$ Manfaat dari penggunaankombinasi obat yangmemiliki efek sinergis ini adalah berkurangnya total obat anestesi yang digunakan dan dapat juga mengurangi efek samping yang ditimbulkan. ${ }^{14}$

Teknik co-induction dengan menggunakan dua atau lebih obat anestesi pada saat induksi anestesi telah banyak dilaporkan, termasuk penggunaan midazolam sebagai salah satu obat co-induction. Pemberian dosis kecil propofol sebelum induksi dengan menggunakan propofol (auto coinduction) dilaporkan juga dapat 
mengurangi dosis total induksi dan perubahan hemodinamik yang terjadi. ${ }^{15}$

Penelitian ini membandingkan midazolam co-induction dan propofol autocoinduction, dengan tujuan untuk mendapatkan alternatif pilihan teknik induksi anestesi dimana didapatkan hasil yang lebih murah dari segi biaya, namun tetap aman dari segi perubahan hemodinamik dan jumlah dosis obat induksi yang digunakan.

Setelah dilakukan penyaringan didapatkan 52 pasien yang memenuhi kriteria inklusi, dan dibagi ke dalam dua kelompok. Dari 52 pasien yang menjadi peserta penelitian didapatkan karakteristik fisik (umur, berat badan, BMI, tinggi badan, jenis kelamin), dan skor ASA yang secara statistik tidak ada perbedaan yang bermakna, dengan kata lain subjek yang diambil menjadi sampel bersifat homogen.

Pada penelitian ini, pada kelompok midazolam coinduction didapatkan tekanan darah sistolik pascainduksi terjadi penurunan sekitar 19,46\% dimana rerata TDS $99.31 \mathrm{mmHg}$ (SD 17.23), sedangkan untuk kelompok propofol autocoinduction tekanan darah sistolik pascainduksi terjadi penurunan sekitar $16.53 \%$, dengan rerata $100.56 \mathrm{mmHg}$ (SD 5.07). Secara statistik perubahan tekanan darah sistolik pada kedua kelompok ini tidak berbeda bermakna.

Tekanan darah diastolik kelompok midazolam mengalami penurunan sebesar $14.51 \%$ dimana rerata 66.15 mmHg (SD 10.41) sedangkan untuk kelompok propofol sebesar $18.72 \%$ dengan rerata $62.62 \mathrm{mmHg}$ (SD 6.054). Secara statistik perubahan tekanan darah diastolik pada kedua kelompok ini juga tidak berbeda bermakna.
Pada penelitian oleh Rillin karo dkk, didapatkan penurunan tekanan darah sistolik lebih rendah sekitar $10 \%$ pada pemberian predosing propofol. Pada penelitian oleh Anderson, pada pemberianpropofol autocoinduction penurunan tekanan darah sistolik sekitar $12 \%$. Dari dua penelitian ini secara statistik juga tidak didapatkan perbedaan yang bermakna, dan hasil ini sama dengan hasil pengamatan pada penelitian ini. ${ }^{5,10}$

Untuk perbandingan MAP terdapat perbedaan yang bermakna secara statistik, dimana kelompok midazolam mengalami penurunan $17.01 \%$ dengan rerata $79.96 \mathrm{mmHg}$ (SD 9,21), sedangkan kelompok propofol mengalami penurunan $18.31 \%$ dengan rerata $73.96 \mathrm{mmHg}$ (SD 5.03).

Perbedaan signifikan dari perubahan antara 2 kelompok ini bisa disebabkan oleh penurunan tekanan diastolik pada kelompok propofol cenderung lebih besar dibandingkan dengan kelompok midazolam, dimana rumus MAP sendiri merupakan 2 kali diastolik ditambah sistolik dibagi 3, sehingga perubahan tekanan darah diastolik cukup mempengaruhi perubahan MAP.

Pada penelitian ini pengunaan jumlah propofol pada kelompok midazolam dengan rerata $8.04 \mathrm{ml}$ (SD 1.755) sedangkan kelompok propofol $8.31 \mathrm{ml}$ (SD 1.850). Secara statistik tidak didapatkan perbedaan yang bermakna. Total dosis rata-rata pada kedua kelompok hampir sama yaitu 80-90 mg. Hasil ini hampir sama dengan penelitian yang dilakukan oleh Sanket, dkk, pada pemberian propofol autocoinduction jumlah total dosis propofol yang digunakan dengan rerata $81.37 \mathrm{mg}$ (SD 15.82). ${ }^{9}$ 
Penelitian oleh Amatya dkk didapatkan hasil yang berbeda, dimana rerata total dosis propofol pada midazolam $\mathrm{co}^{-}$ induction $80.50 \mathrm{mg}$ (SD 38.149), sedangkan untuk kelompok propofol auto-coinduction rerata total dosis $111.71 \mathrm{mg}$ (SD 27.37). Hal ini menunjukkan penggunaan midazolam co-induction menurunkan $27 \%$ dosis propofol yang digunakan dibandingkan dengan propofol auto-coinduction. ${ }^{15}$

Perbedaan pengunaan dosis propofol sendiri tergantung dari beberapa hal, diantaranya tujuan akhir sedasi, umur pasien, kecepatan injeksi, dan penggunaan premedikasi. Ada beberapa perbedaan pada penelitian oleh Amatya dan penelitian ini, penelitian oleh Amatya menggunakan premedikasi pethidin sebelum induksi. Rerata berat badan pada penelitian ini juga lebih tinggi $60.19 \mathrm{Kg}$, sedangkan pada penelitian Amatya rerata berat badan $54.48 \mathrm{Kg}$. Perbedaan ini yang mungkin menjadi alasan mengapa pada penelitian oleh amatya terjadi perbedaan penggunaan total dosis propofol. ${ }^{15}$

Dari hasil penelitian juga didapatkan kelompok midazolam dan propofol sama sama tidak sampai menghabiskan 1 vial propofol $(20 \mathrm{ml})$ untuk induksi anestesi. Namun yang menjadi perbedaan adalah pada kelompok midazolam ditambahkan 1 ampul midazolam pada penggunaannya. Bila dibandingkan, kelompok midazolam secara akan lebih mahal, dimana harga 1 vial propofol Rp. 13,200 ditambah harga midazolam Rp. 5250, sehingga total harga Rp. 18.450, sedangkan kelompok propofol dengan harga Rp. 13.200 saja.

Bila dihitung harga sesuai jumlah volume yang digunakan, kelompok propofol secara signifikan $(\mathrm{p}<0,05)$ menunjukkan perbedaan dari kelompok midazolam. Kelompok propofol memiliki rerata harga Rp. 7.082 (SD 1.403) sedangkan kelompok midazolam memiliki harga Rp. 7.890 (SD 1448).

Propofol setelah dibuka dari ampulnya sebaiknya digunakan untuk satu pasien saja. Dari penelitian ini juga didapatkan bahwa sisa propofol pada kelompok midazolam lebih banyak dari pada kelompok propofol.

\section{KESIMPULAN}

Penggunaan propofol auto-coinduction dapat digunakan sebagai teknik alternatif induksi anestesi di samping pengunaan midazolam sebagai coinduction pada pasien yang akan dilakukan anestesi umum di kamar operasi RSUD Dr. Soetomo, hal ini dikarenakan lebih aman, tidak berpengaruh banyak terhadap hemodinamik, dan biaya lebih murah.

\section{DAFTAR PUSTAKA}

1. Amrein R, Hetzel W, Allen SR. Co-induction of Anaesthesia: The Rationale. Eur J Anaesthesiology Suppl. Nov 1995;12:5-11.

2. Nathan N, Odin I. Induction of Anaesthesia: A Guide to Drug Choice. Drugs. 2007; 67(5): 701723

3. Myles, PS, Hendrata, M., Bennett, AM., Langley M., Buckland., MR. Postoperative nausea and vomiting. Propofol or thiopentone: does choice of induction agent affect outcome?. Anaesth Intensive Care.1996;24(3):355-9.

4. Warner D.S. Propofol: its role in changing the practice of anesthesia. Anesthesiology 2008; 109 (6):1132-6.

5. Anderson L, Robb H. A Comparison of Midazolam Coinduction With Propofol Predosing For Induction Of Anaesthesia. 
Anesthesia. Blackwell Science Ltd.1998; 53(11):1117-20

6. Whitwam JG. Co-induction of anaesthesia: day-case surgery. Eur J Anaesthesiol Suppl. 1995;12:2534.

7. Departemen Anestesi dan Terapi Intensif Universitas Airlangga. Data Operasi elektif RSUD Dr. Soetomo juni-desember tahun 2017. Surabaya: Universitas Airlangga; 2017.

8. Healy TE,Knight PR. Clinical Pharmacology and anesthesia technique. Wylie ChurchillDavidson's A Practice of Anesthesia 7th Edition. London: Arnold Press. 2003

9. Mehta SH, Dabhi PG, Golwala MP, Upadhyay MR. Effect of priming Principle on the induction dose Requirement of Propofol. Int J Res Med. 2015; 4(1): 69-73

10. Karlo R, Singh NR, Singh KM, Singh TH. Priming effects of propofol during induction of anesthesia. Journal of Medical Society.2015; 29 (2): 92-95

11. Gillies GW, Lees NW. The effect of speed of injection of propofol. A comparison with etomidate. Anesthesia.1989;44: 386-8

12. Hug $\mathrm{CC}$, McLeskey $\mathrm{CH}$, Nahworld, et all. Haemodynamic effects of propofol-data from 24771 patients. Anesthesia and analgesia. 1993; 77 (4): S21-9.

13. Fairfield JE, Dritsas A, Beale RJ. Haemodynamic effects of propofol: induction with 2.5 mg.Kg-1. British Journal of anaesthesia. 1991; 67: 618-20

14. Short TG, Chui PT. Propofol and midazolam act synergistically in combination. Br J anaesth. 1991; 67(5):539-45.

15. Amatya A, Marhatta MN, Shrestha GS. A comparison of midazolam Co-induction with propofol priming in propofol induced anesthesia. J Nepal Health Res Counc. 2014; 12(26): 44-8 